\title{
Changes in plasma albumin levels in early detection of infectious complications after laparoscopic colorectal cancer surgery with ERAS protocol
}

\author{
Mateusz Wierdak ${ }^{1}$ Magdalena Pisarska ${ }^{1,2}$ - Beata Kuśnierz-Cabala ${ }^{3}$ Jan Witowski ${ }^{1,2}$. Jadwiga Dworak ${ }^{1}$. \\ Piotr Major ${ }^{1,2} \cdot$ Piotr Małczak $^{1,2} \cdot$ Piotr Ceranowicz ${ }^{4}$ Andrzej Budzyński ${ }^{1,2} \cdot$ Michał Pędziwiatr $^{1,2}$ (C)
}

Received: 24 July 2017 / Accepted: 3 January 2018 / Published online: 16 January 2018

(c) The Author(s) 2018. This article is an open access publication

\begin{abstract}
Background Combination of laparoscopic approach with ERAS protocol in colorectal surgery allows for an early discharge. However there is a risk that some of the discharged patients are developing, asymptomatic at the time, infectious complications. This may lead to a delay in diagnostics and proper treatment introduction. We aimed to assess the usefulness of preoperative plasma albumin concentration and their changes as indicators of infectious complications in patients undergoing colorectal cancer surgery.

Methods Prospective analysis included 105 consecutive patients who underwent laparoscopic colorectal cancer resection between August 2014 and September 2016. In all cases standardised 16-item perioperative care ERAS protocol was used (mean compliance $>85 \%$ ). Patients with IBD, distant metastases, undergoing emergency or multivisceral resection were excluded. Blood samples were collected preoperatively and on POD 1,2,3. Plasma albumin concentration was measured. Patients were divided into two groups depending on the presence of infectious complications. We analysed the differences in the levels of albumin and the dynamics of changes.

Results Group $1-82$ not complicated patients, Group 2-23 patients with at least one infectious complication. Preoperatively, there were no significant differences in the levels of serum albumin between those groups (Group $1-38.7 \pm 4.9 \mathrm{~g} / \mathrm{l}$; Group 2-37.7 $\pm 5.0 \mathrm{~g} / \mathrm{l}$ ). In postoperative period, decrease was observed in both (POD 1: Group 1-36.5 $\pm 4.2 \mathrm{~g} / \mathrm{l}$, Group 2-34.7 $\pm 4.2 \mathrm{~g} / \mathrm{l}, p=0.07$; POD 2: Group $1-36.2 \pm 4.1 \mathrm{~g} / \mathrm{l}$, Group 2-32.6 $\pm 5.6 \mathrm{~g} / \mathrm{l}, p=0.01$; POD 3: Group $1-36.0 \pm 4.4 \mathrm{~g} / \mathrm{l}$, Group $2-30.9 \pm 3.5 \mathrm{~g} / \mathrm{l}, p=0.01$ ). The decrease was significantly greater in Group 2 on POD 2 and 3.

Conclusions We showed that a regular measurement of albumin in the early postoperative days may be beneficial in the detection of postoperative infectious complications. Although changes in albumins are observed early after surgery, this parameter is relatively unspecific.
\end{abstract}

Keywords Colorectal cancer $\cdot$ Laparoscopy $\cdot$ Infectious complications $\cdot$ Markers $\cdot$ Albumins

This study has been awarded the Best Poster Presentation at the EAES Congress 2017 in Frankfurt.

Michał Pędziwiatr

michal.pedziwiatr@uj.edu.pl

1 2nd Department of General Surgery, Jagiellonian University Medical College, Kopernika 21, 31-501 Kraków, Poland

2 Centre for Research, Training and Innovation in Surgery (CERTAIN Surgery), Kraków, Poland

3 Department of Diagnostics, Chair of Clinical Biochemistry, Jagiellonian University Medical College, Kraków, Poland

4 Department of Physiology, Jagiellonian University Medical College, Kraków, Poland
Colorectal cancer surgery is associated with a relatively high morbidity rate, which depends on multiple factors and can occur in $30-40 \%$ of patients $[1,2]$. One of the significant components affecting those parameters is the surgical technique. It has been shown that the laparoscopic approach is correlated with reduced morbidity [3, 4]. Moreover, the implementation of multimodal perioperative care protocols enhanced recovery after surgery (ERAS) further decreases postoperative complications by approximately $20-40 \%$ and leads to early hospital discharge after $2-5$ days [5-8]. These factors markedly shortened length of stay (LOS). Some complications (i.e. anastomotic leakage) can occur late after surgery, even on postoperative day (POD) $8-12$. This 
means that in most cases they are diagnosed after discharge [9]. For these reasons, markers that allow early detection of complications and prediction of their severity, ideally before patients become symptomatic, are the area of interest for many surgeons.

Albumin, which is mostly used as a nutritional marker and a predictor for outcomes, is a protein which immediately responds to surgical stress. An albumin drop is observed in most major abdominal surgeries within the first postoperative hours [10-12]. Although pathophysiological basics of albumin kinetics are well-established, this parameter is rarely used as a marker of complications in the early postoperative period. Also, the albumin level correlates with the surgical trauma and postoperative stress response [13]. It is important in the context of laparoscopy and ERAS protocol, since they both significantly reduce the degree of surgical stress $[14,15]$. That is why it seems reasonable to establish whether regular assessments of albumin level in the early postoperative phase are clinically relevant.

\section{Aim}

The aim of this study was to evaluate the usefulness of albumin level measurements as an early predictor of infectious complications in patients with colorectal cancer undergoing laparoscopic surgery with ERAS protocol.

\section{Materials and methods}

The study was conducted in a tertiary referral centre (university hospital). Consecutive patients undergoing laparoscopic resection for colorectal cancer were prospectively analysed. Inclusion criteria were age over 18 years old, elective laparoscopic surgery for verified colorectal adenocarcinoma and ERAS protocol in perioperative care. We excluded patients who underwent open or emergency surgery and those in which resection exceeding the large bowel (T4) was required. Patients with inflammatory bowel disease were excluded from the study as well as cases where it was not possible to implement ERAS protocol (i.e. due to hospitalisation in ICU). Other exclusion criteria included distant metastases (M1), rectal cancer treated with transanal endoscopic microsurgery, conversion to open resection, patients with an active infection or autoimmune systemic disease. Moreover, we excluded patients in whom infectious complications were diagnosed within the first $48 \mathrm{~h}$ postoperatively.

A laparoscopic approach with five or six trocars and medial to lateral technique was used [16]. All patients had the exact same perioperative care ERAS protocol (Table 1), which has been used in our department for 5 years. Mean compliance with the protocol is over $80 \%$ [17].

Blood samples for albumin measurements were drawn from the patients four times: on the day of surgery and on the three following PODs. Albumin measurements were included in the routine biochemistry panel; they were performed in serum on the day of blood collection using the automated analyser Cobas 6000 (Roche Diagnostics, Basel, Switzerland).

Table 1 ERAS protocol used in our unit

1 Preoperative counselling and patient's education

2 No bowel preparation (oral lavage in the case of low rectal resection with TME and defunctioning loop ileostomy)

3 Preoperative carbohydrate loading (400 $\mathrm{ml}$ of Nutricia preOp® $2 \mathrm{~h}$ prior surgery)

4 Antithrombotic prophylaxis (Clexane ${ }^{\circledR} 40 \mathrm{mg}$ sc. starting in the evening prior surgery)

5 Antibiotic prophylaxis (preoperative cefuroxime $1.5 \mathrm{~g}+$ metronidazole $0.5 \mathrm{~g}$ iv. 30-60 min prior surgery)

6 Laparoscopic surgery

7 Balanced intravenous fluid therapy ( $<2500 \mathrm{ml}$ intravenous fluids during the day of surgery, less than 150 mmol sodium)

8 No nasogastric tubes postoperatively

9 No drains left routinely for colonic resections, one drain placed for $<24 \mathrm{~h}$ in case of TME

10 Transversus abdominis plane (TAP) block, epidural anaesthesia in cases with high risk of conversion

11 Avoiding opioids, multimodal analgesia (oral when possible-paracetamol $4 \times 1 \mathrm{~g}$, ibuprofen $2 \times 200 \mathrm{mg}$, metamizole $2 \times 2.5 \mathrm{~g}$, or ketoprofen $2 \times 100 \mathrm{mg}$ )

12 Prevention of postoperative nausea and vomiting (PONV) (dexamethasone $8 \mathrm{mg}$ iv., ondansetron $8 \mathrm{mg}$ iv., metoclopramide $10 \mathrm{mg}$ iv.)

13 Postoperative oxygenation therapy (4-6 1/min)

14 Early oral feeding (oral nutritional supplement $4 \mathrm{~h}$ postoperatively, light hospital diet and oral nutritional supplements on the first postoperative day, full hospital diet on the second postoperative day)

15 Urinary catheter removal on the first postoperative day

16 Full mobilisation on the first postoperative day (getting out of bed, going to toilet, walking along the corridor, at least $4 \mathrm{~h}$ out of bed) 
Serum samples were obtained by centrifuging blood, collected without anticoagulant, for $10 \mathrm{~min}$ at $4000 \mathrm{rpm}$ on a MPW 351e centrifuge (MPW Med. Instruments, Warsaw, Poland; Rotor No. 12,436). The reference interval for albumin was $35-50 \mathrm{~g} / \mathrm{l}$.

Patients were divided into Groups 1 and 2 that included patients without and with infectious complications, respectively. The diagnosis of these complications and assessment of their severity was performed according to ECDC guidelines [18].

Groups were compared for age, sex, body mass index (BMI), American Society of Anaesthesiologists (ASA) score, type of surgery, tumour staging, operative time and intraoperative blood loss. Differences in albumin level between groups were analysed on consecutive PODs. Due to the high variability in preoperative measurements, $\Delta$-increments were calculated each day (i.e. $\triangle \mathrm{POD} 1$ : difference of concentration on POD1 and POD0; $\triangle \mathrm{POD} 2$ : difference of concentration on POD2 and POD0 etc). Additionally, albumin level ratios were calculated (i.e. POD1/0, POD $3 / 0$, POD $3 / 1$ etc.).

\section{Statistical analysis}

All data were analysed with Statsoft STATISTICA v.12. The results are presented as mean \pm standard deviation (SD), median and interquartile range (IQR). The study of categorical variables used the Chi-square test of independence. The Shapiro-Wilk test was used to check for a normal distribution of data and the Student $t$ test was used for normally distributed quantitative data. For non-normally distributed quantitative variables, the Mann-Whitney U test was used. For dependent variables the Friedman test was used. A receiver operating characteristic (ROC) curve was applied to obtain the area under the curve (AUC) and determine the best cut-offs. Results were considered statistically significant when $\mathrm{p}$ value was less than 0.05 .

The study was approved by the local Ethics Review Committee (Approval Number KBET/211/B/2014). All procedures were performed in accordance with the ethical standards laid down in the 1964 Declaration of Helsinki and its later amendments.

\section{Results}

192 patients in our department underwent colorectal resection between August 2014 and September 2016. 41 of them did not fulfil inclusion criteria and were initially excluded. 44 were excluded during surgery. Two patients were excluded because ERAS protocol was not implemented in the postoperative period. Patients' flow through the study and reasons for exclusion are shown in Fig. 1.

Groups 1 and 2 consisted of $82(78.1 \%)$ and 23 (21.9\%) patients, respectively. Table 2 shows a demographic analysis of groups. No significant differences were noticed regarding their demography, ASA scale, type of performed surgery, operative time, intraoperative blood loss and cancer stage. However, there were significant differences between the groups in median LOS (4 vs. 9 days, $p<0.001)$ and readmission rate ( 4.9 vs. $17.4 \%, p=0.046)$. In addition, we did not notice differences in mean intravenous fluids transfused during the surgical procedure and first $24 \mathrm{~h}$ postoperatively $(2134 \pm 665$ vs. $2333 \pm 901 \mathrm{ml}, p=0.42)$. The compliance with restrictive intravenous fluid therapy according to ERAS protocol was 91.4 vs. $87.1 \%$ in Group 1 and 2, respectively $(p=0.51)$.

The overall infectious complication rate was $21.9 \%$. An analysis of infectious complications is presented in Table 3 .

Laboratory measurements are presented in Table 4. Before surgery (POD 0 measurement), albumin levels were comparable between groups $(p=0.58)$. On POD 1 , the albumin levels decreased in both groups, but the difference between Groups was not statistically significant $(p=0.07)$. On POD 2 and 3, the albumin levels in Group 1 were lower than in Group $2(p=0.001, p=0.00001)$ (Fig. 2). Friedman's ANOVA showed differences in consecutive albumin measurements in both groups $(p=0.00012$ in Group 1 and $p<0.00001$ in Group 2). When $\Delta$-albumin increments were analysed, the differences were significant only in Group 2 ( $p=0.38$ in Group 1 and $p=0.00006$ in Group 2). Similarly, differences in albumin ratios were statistically significant only in Group 2 ( $p=0.38$ in Group 1 and $p=0.00006$ in Group 2) (Figs.3, 4).

A ROC curve was used to determine the optimal cutoff of albumin levels, $\Delta$-albumin increments and albumin ratios in consecutive days. This analysis showed that measurements on POD3 were characterised by highest specificity and sensitivity. Figures 5, 6, 7 and 8 show ROC curves and their characteristics.

\section{Discussion}

This study showed that regardless of the occurrence of complications, there was a reduction in the albumin level in the early PODs after laparoscopic colorectal resection with perioperative ERAS protocol. In addition, it was more pronounced in patients with complications. Moreover, we observed that among uncomplicated cases the level of albumins after initial rapid drop in the first POD remained stable over the next days. In patients who developed complications, albumins decreased further in the consecutive days. That 


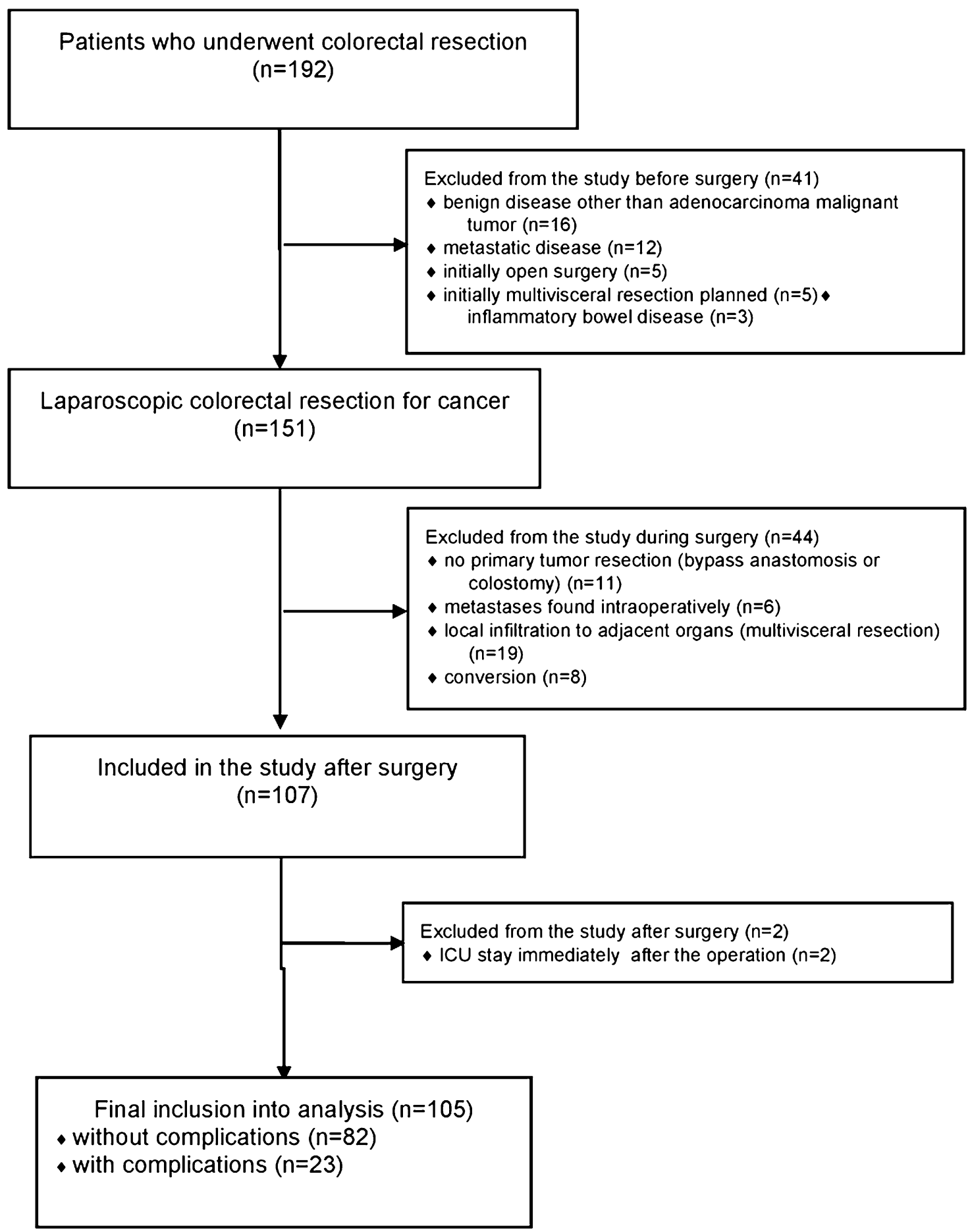

Fig. 1 Patients flow through the study

also reflected on the analysis of albumin level derivatives such as $\Delta$-albumin increments and ratios.

Most studies focus on the preoperative level of hypoalbuminemia and its influence on outcomes. Relatively few publications analysed it as a potential marker of early adverse events, and therefore it is seldom used as a biomarker of complications $[12,13,19,20]$. However, albumin, which is considered a negative acute phase protein with a halflife of 20 days, seems to have perfect characteristics for a useful biomarker [19]. It is easy to measure, widely available and inexpensive. In addition, its kinetics allows for measurements within first postoperative hours $[13,21]$. 
Table 2 Demographic analysis of patient groups

\begin{tabular}{|c|c|c|c|}
\hline Parameter & $\begin{array}{l}\text { Group } 1 \\
\text { (uncomplicated) }\end{array}$ & $\begin{array}{l}\text { Group } 2 \\
\text { (complicated) }\end{array}$ & $p$ value \\
\hline Number of patients [n (\%)] & $82(78.1 \%)$ & $23(21.9 \%)$ & - \\
\hline Females [n (\%)] & $39(47.6 \%)$ & $12(52.2 \%)$ & 0.69572 \\
\hline Males [n (\%)] & $43(52.4 \%)$ & $11(47.8 \%)$ & \\
\hline Mean age (years $\pm S D$ ) & $63.2 \pm 13.4$ & $65.3 \pm 13.5$ & 0.62947 \\
\hline $\mathrm{BMI}\left(\mathrm{kg} / \mathrm{m}^{2} \pm \mathrm{SD}\right)$ & $26.7 \pm 5.0$ & $26.8 \pm 5.0$ & 0.75312 \\
\hline ASA $1[\mathrm{n}(\%)]$ & $1(1.2 \%)$ & $1(4.3 \%)$ & 0.6609 \\
\hline ASA $2[\mathrm{n}(\%)]$ & $53(64.6 \%)$ & $14(60.9 \%)$ & \\
\hline ASA $3[\mathrm{n}(\%)]$ & $27(33 \%)$ & $7(30.4 \%)$ & \\
\hline ASA $4[\mathrm{n}(\%)]$ & $1(1.2 \%)$ & $1(4.3 \%)$ & \\
\hline Any comorbidity [n (\%)] & $64(78 \%)$ & $17(73.9 \%)$ & 0.67663 \\
\hline Cardiovascular [n (\%)] & $30(36.6 \%)$ & $8(34.8 \%)$ & 0.87442 \\
\hline Hypertension [n (\%)] & $42(51.2 \%)$ & $12(52.2 \%)$ & 0.93331 \\
\hline Diabetes [n (\%)] & $15(18.3 \%)$ & $5(21.7 \%)$ & 0.71028 \\
\hline Pulmonary disease [n (\%)] & $6(7.3 \%)$ & $3(13 \%)$ & 0.38584 \\
\hline Renal disease [n (\%)] & $6(7.3 \%)$ & $2(8.7 \%)$ & 0.82658 \\
\hline Liver disease [n (\%)] & $4(4.9 \%)$ & $1(4.3 \%)$ & 0.91647 \\
\hline AJCC Stage I [n (\%)] & $37(45.1 \%)$ & $10(43.5 \%)$ & 0.63179 \\
\hline AJCC Stage II [n (\%)] & $24(29.3 \%)$ & $5(21.7 \%)$ & \\
\hline AJCC Stage III [n (\%)] & $21(25.6 \%)$ & $8(34.8 \%)$ & \\
\hline Colonic resection $[\mathrm{n}(\%)]$ & $53(64.6 \%)$ & $16(69.6 \%)$ & 0.65748 \\
\hline Rectal resection [n (\%)] & $29(35.4 \%)$ & $7(30.4 \%)$ & \\
\hline Mean operative time $(\min \pm S D)$ & $194.4 \pm 56.7$ & $215.3 \pm 73.3$ & 0.44429 \\
\hline Median operative time [min (IQR)] & $190(160-230)$ & $180(170-275)$ & \\
\hline Mean intraoperative blood loss $(\mathrm{ml} \pm \mathrm{SD})$ & $113.0 \pm 118.4$ & $128.4 \pm 107.6$ & 0.55006 \\
\hline Median intraoperative blood loss [ml (IQR)] & $100(50-150)$ & $100(50-200)$ & \\
\hline Mean length of hospital stay (days, range) & $4.8 \pm 4.0$ & $10.8 \pm 6.7$ & 0.00003 \\
\hline Median length of hospital stay (days, IQR) & $4(3-6)$ & $9(6-18)$ & \\
\hline Readmission [n (\%)] & $4(4.9 \%)$ & $4(17.4 \%)$ & 0.04561 \\
\hline
\end{tabular}

Table 3 Types of complications

\begin{tabular}{lc}
\hline Anastomotic leakage & $9(8.6 \%)$ \\
Surgical site infection-deep or superficial & $6(5.7 \%)$ \\
Intraperitoneal abscess & $2(1.9 \%)$ \\
Urinary tract infection & $3(2.8 \%)$ \\
Pneumonia & $2(1.9 \%)$ \\
Infectious diarrhoea (C. difficile) & $1(1.0 \%)$ \\
\hline
\end{tabular}

Unfortunately, albumin is rather unspecific, and therefore it cannot exactly predict the underlying cause of its changes.

We focused on albumin, since it is an easy to assess biochemical marker, familiar to most clinicians, and routinely measured in every laboratory. However, apart from albumin, there are other negative acute phase proteins such as transferrin, transthyretin, retinol-binding protein, antithrombin, transcortin, cortisol-binding globulin, transthyretin [22]. Although their decrease is observed in inflammation and they were extensively studied some time ago, according to our knowledge they were never investigated as useful markers of inflammatory complications after surgical procedures. This still needs to be investigated whether other negative acute phase proteins may in the future be used for early detection of complications.

According to previous studies, early postoperative albumin drop is associated with altered metabolism, blood loss, dilution or redistribution into the third space [10, 12, 13, 23]. Albumin production is inhibited in an acute condition, which enables increased production of acute phase proteins such as CRP or fibrinogen. It has been shown in experimental studies that $77 \%$ of the postoperative albumin decrease was due to redistribution, while 18 and $6 \%$ were attributed to blood loss and catabolism, respectively [10]. Interestingly, redistribution is strongly correlated with systemic inflammatory response observed in major abdominal surgeries and practically non-existent in minor procedures [10, 23].

In contrast to previously published data, rapid postoperative albumin drop in our study was relatively low, $2 \mathrm{~g} / 1$ $(5.1 \%)$ in Group 1 and $5 \mathrm{~g} / 1$ (12.5\%) in Group 2. This is 
Table 4 Analysis of biochemical parameters

\begin{tabular}{|c|c|c|c|c|}
\hline Parameter & & $\begin{array}{l}\text { Group } 1 \\
\text { (uncomplicated) }\end{array}$ & $\begin{array}{l}\text { Group } 2 \\
\text { (complicated) }\end{array}$ & $p$ value \\
\hline \multirow[t]{4}{*}{ Mean albumin $\pm \mathrm{SD}$ (median, IQR) (g/l) } & POD 0 & $38.7 \pm 4.9(39,36-42)$ & $37.7 \pm 5.0(40,35-41)$ & 0.58702 \\
\hline & POD 1 & $36.5 \pm 4.2(37,34-39)$ & $34.7 \pm 4.2(35,30-37)$ & 0.07131 \\
\hline & POD 2 & $36.2 \pm 4.1(37,34-39)$ & $32.6 \pm 5.6(33,30-36)$ & 0.00996 \\
\hline & POD 3 & $36.0 \pm 4.4(36,34-39)$ & $30.9 \pm 3.5(31,28-32)$ & 0.00004 \\
\hline \multirow[t]{3}{*}{$\Delta$-albumin $\pm \mathrm{SD}($ median $)(\mathrm{g} / \mathrm{l})$} & POD 1 & $-2.6 \pm 4.1(-2,-5$ to 1$)$ & $-3.0 \pm 4.6(-4,-6$ to 0$)$ & 0.68309 \\
\hline & POD 2 & $-2.9 \pm 4.5(-3,-6$ to 0$)$ & $-5.2 \pm 5.3(-6,-8$ to -1$)$ & 0.04953 \\
\hline & POD 3 & $-3.2 \pm 4.4(-3,-6$ to 0$)$ & $-7.2 \pm 4.7(-7,-10$ to -5$)$ & 0.00306 \\
\hline Albumin POD 1/POD 0, mean $\pm \mathrm{SD}($ median, IQR) & & $0.94 \pm 0.09(0.94,0.88-1.02)$ & $0.93 \pm 0.13(0.9,0.85-1)$ & 0.27379 \\
\hline Albumin POD 2/POD 0, mean $\pm \mathrm{SD}$ (median, IQR) & & $0.93 \pm 0.11(0.93,0.84-1.0)$ & $0.83 \pm 0.24(0.86,0.79-0.94)$ & 0.02905 \\
\hline Albumin POD 3/POD 0, mean \pm SD (median, IQR) & & $0.92 \pm 0.11(0.91,0.83-1.0)$ & $0.82 \pm 0.11(0.82,0.76-0.89)$ & 0.00481 \\
\hline Albumin POD 2/POD 1, mean \pm SD (median, IQR) & & $0.99 \pm 0.1(1,0.94-1.05)$ & $0.92 \pm 0.1(0.9,0.86-1.03)$ & 0.01294 \\
\hline Albumin POD 3/POD 1, mean \pm SD (median, IQR) & & $1.0 \pm 0.12(0.97,0.86-1.03)$ & $0.87 \pm 0.08(0.86,0.83-0.91)$ & 0.00002 \\
\hline
\end{tabular}

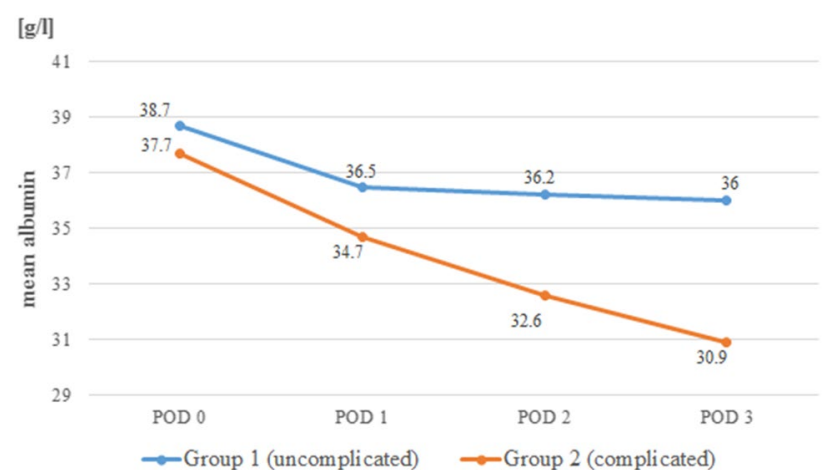

Fig. 2 Mean albumin levels in Group 1 and Group 2 in consecutive days

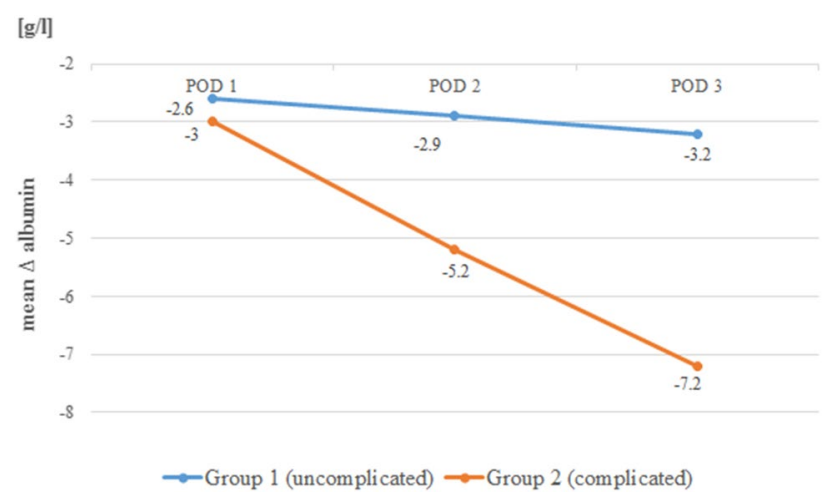

Fig. 3 Mean $\Delta$-albumin increments in Group 1 and Group 2 in consecutive days

different from previously published data, where a $20-35 \%$ drop was observed $[12,13]$. In these studies, however, the greatest decrease in albumin level was observed in patients undergoing liver surgery [19]. There are two potential

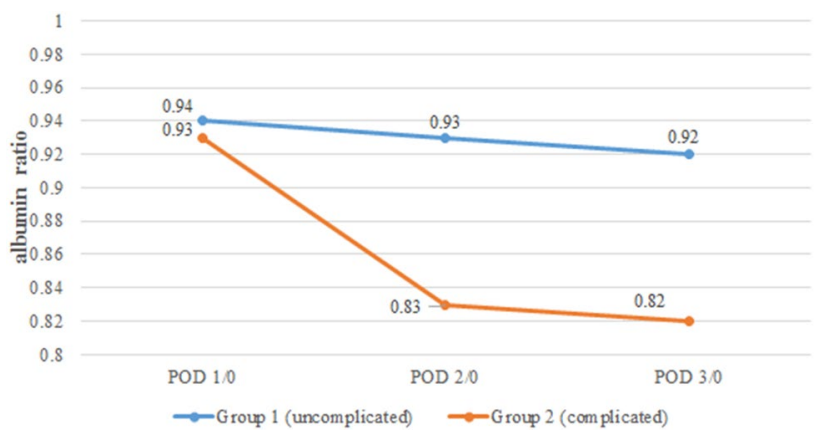

Fig. 4 Albumin ratios in Group 1 and Group 2 in consecutive days

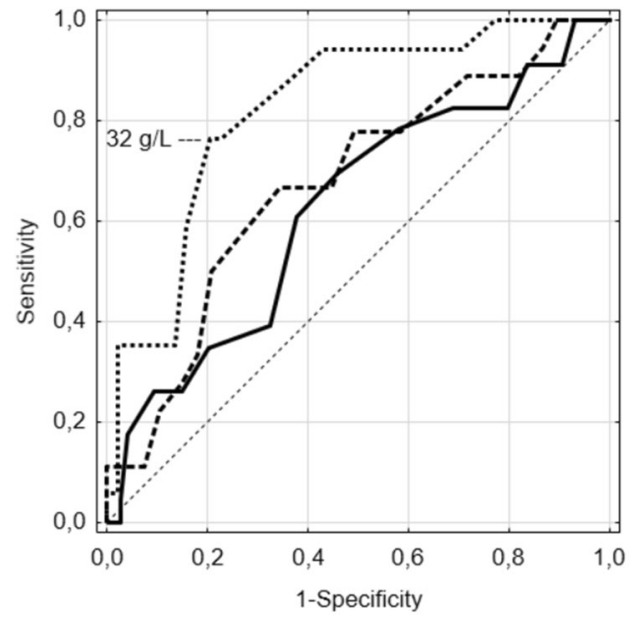

-Albumin POD1, --Albumin POD2, .-Albumin POD3

AUC: POD1 -0,61; POD2 -0,71; POD3 -0,75

Cut-off value POD3 $32 \mathrm{~g} / \mathrm{L}$ (Sensitivity $77 \% /$ Specificity $80 \%$ )

Fig. 5 Receiver operating characteristic (ROC) curve to determine the optimal cut-off of albumin measurements 


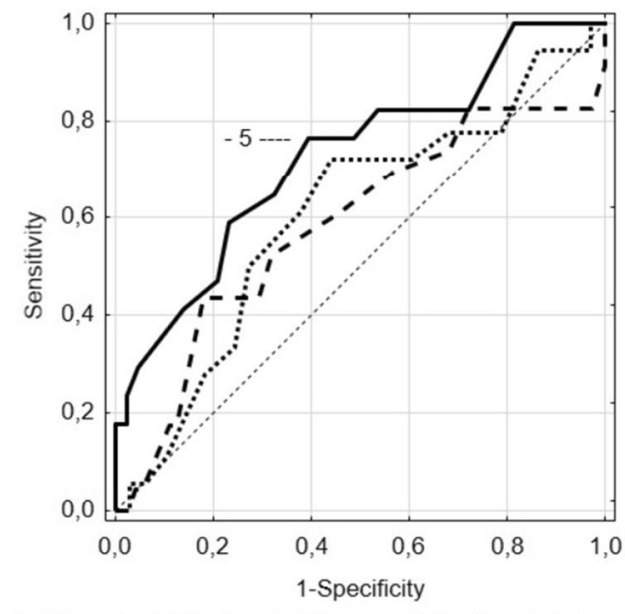

- $\triangle$ Albumin POD1, $\cdots \Delta$ Albumin POD2,- $\Delta$ Albumin POD3

AUC $\Delta$ Albumin : POD1 - 0,56; POD2 - 0,64; POD3 -0,68

Cut-off value $\Delta$ Albumin POD3 - $-5 \mathrm{~g} / \mathrm{L}$ (Sensitivity $76 \%$ / Specificity $61 \%$ )

Fig. 6 Receiver operating characteristic (ROC) curve to determine the optimal cut-off of $\Delta$-albumin measurements

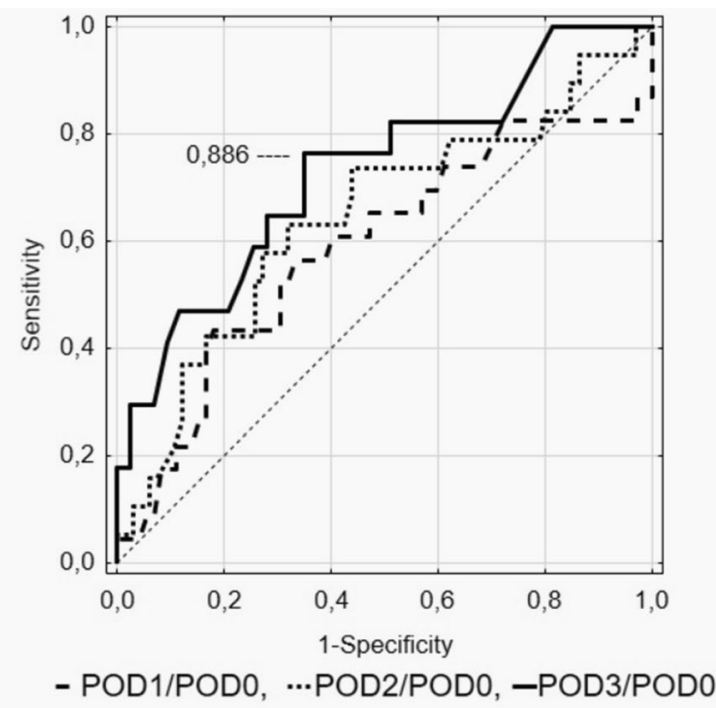

AUC: POD1/POD0 -0,57 ; POD2/POD0 -0,66; POD3/POD -0,68

Cut-off value POD3/POD0 0,886 g/L (Sensitivity $77 \%$ / Specificity 65\%)

Fig. 7 Receiver operating characteristic (ROC) curve to determine the optimal cut-off of albumin ratio measurements (POD0)

factors that might contribute to the diminished albumin drop in our patients. Firstly, all our patients underwent laparoscopic colorectal surgery. It is known that laparoscopy has a positive impact on postoperative stress response, and so may contribute to a decreased albumin drop [24]. In addition, in all our patients ERAS protocol has been used, with a

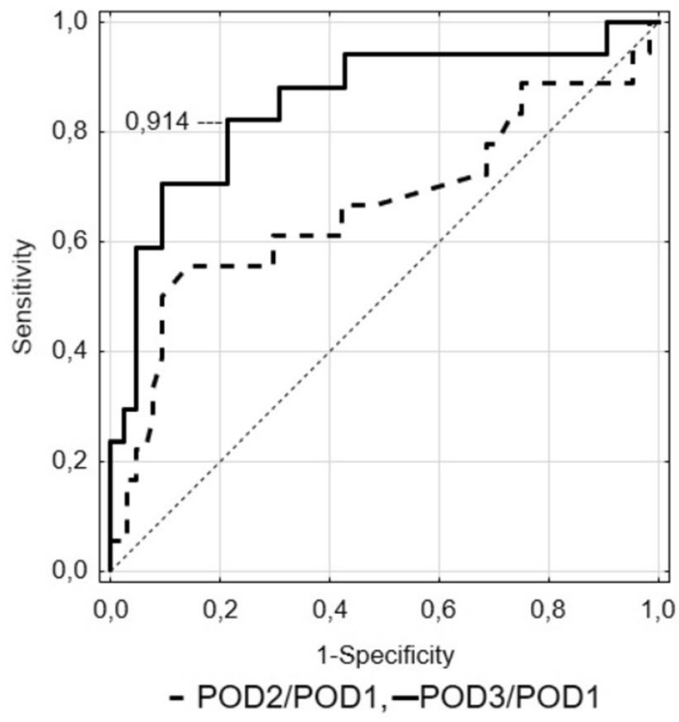

AUC: POD2/POD1 - 0,69; POD3/POD1 - 0,76;

Cut-off value POD3/POD1 - 0,914 (Sensitivity 82\%/ Specificity 79\%)

Fig. 8 Receiver operating characteristic (ROC) curve to determine the optimal cut-off of albumin ratio measurements (POD1)

high level of adherence. ERAS has been shown to decrease stress response in the postoperative period [14]. Moreover, one of the key elements of ERAS is balanced/restrictive fluid therapy [25-27]. In our opinion, this might have also prevented excessive hemodilution in the early hours after surgery. All these factors may have an impact on postoperative albumin levels.

The fundamental question is whether the use of albumins in the early postoperative period is clinically relevant. It seems that there is no clear answer to this problem. On the one hand, the kinetics of albumins makes them perfectly suitable as early markers. On the other hand, it drops in any increased stress reaction, making albumins less specific. In addition, their relationship with the extent of surgery, blood loss and fluid resuscitation in the postoperative period can introduce many confounding variables which may bias the interpretation of results. However, we observed that it is not the first drop in the albumin level that differs between complicated and uncomplicated patients but rather the trend over the next days. If the level continues to decrease, it may seem that it is due to an underlying complication, which may require further diagnostics or prolonged observation in hospital.

The ROC curve analysis showed that measurements on POD3 are characterised by the best sensitivity and specificity. Because albumin measurements are rather unspecific in determining the development of complications, we tried to increase the specificity using their derivatives. When $\Delta$-albumin increments were analysed, thus including the 
baseline levels of albumins in measurements, we observed that the sensitivity and specificity on POD 3 were at the highest level. Similar observations were made when ratios were calculated. Unfortunately, none of these derivatives provided better parameters. In our opinion, it is best to measure albumin levels on consecutive PODs in order to monitor their level when searching for postoperative complications. Other calculations, with the use of albumin levels, do not improve the results.

Our study has certain limitations which are typical for a single centre study. We did not assess food charts and dietetic preferences of patients. They may have introduced confounding factor to the analysis. The study sample is relatively low, especially in the group including patients with complications. Besides, we focused only on infectious complications, since albumin, being the negative acute phase protein, is strongly correlated with inflammatory response. We did not analyse complications with less impact on inflammatory status.

Therefore, our observations should be repeated in larger cohorts of patients. On the other hand, all patients were selected cases, undergoing a similar type of the minimally invasive colorectal procedure. The baseline characteristics of groups of patients with and without complications, as well as the adherence to the protocol were comparable, allowing us to draw the conclusion that the differences are closely related to occurring complications. In addition, types of complications are quite heterogeneous (e.g. surgical site infection vs. anastomotic leakage). The whole idea of the study was based on the influence of inflammatory reaction on changes in albumin levels. Therefore, when planning the study, we decided to focus only on inflammatory complications because albumin, being the negative acute phase protein, is strongly correlated with inflammatory response. We agree that exclusion of other complications (e.g. prolonged ileus) might have influenced the final results. For this reason, it has to be further investigated whether benefits of albumin measurements in the determination of postoperative complications can be found in all patients, regardless of the severity, type and underlying cause of complication.

\section{Conclusion}

Our study showed that a regular measurement of albumin levels in the early postoperative days may be beneficial in the detection of postoperative infectious complications. Although changes in albumins are observed early after surgery, this parameter is relatively unspecific. However, consecutive measurements of albumin levels may very well serve as an auxiliary biomarker in the monitoring of patients after laparoscopic colorectal resections.

\section{Compliance with ethical standards}

Disclosures Mateusz Wierdak, Magdalena Pisarska, Beata KuśnierzCabala, Jan Witowski, Jadwiga Dworak, Piotr Major, Piotr Małczak, Piotr Ceranowicz, Andrzej Budzyński, Michał Pędziwiatr declare that they have no conflicts of interest or financial ties to disclose.

Open Access This article is distributed under the terms of the Creative Commons Attribution 4.0 International License (http://creativecommons.org/licenses/by/4.0/), which permits unrestricted use, distribution, and reproduction in any medium, provided you give appropriate credit to the original author(s) and the source, provide a link to the Creative Commons license, and indicate if changes were made.

\section{References}

1. Longo WE, Virgo KS, Johnson FE, Oprian CA, Vernava AM, Wade TP, Phelan MA, Henderson WG, Daley J, Khuri SF (2000) Risk factors for morbidity and mortality after colectomy for colon cancer. Dis Colon Rectum 43:83-91

2. ERAS Compliance Group (2015) The impact of enhanced recovery protocol compliance on elective colorectal cancer resection: results from an international registry. Ann Surg 261:1153-1159. https://doi.org/10.1097/SLA.0000000000001029

3. Arezzo A, Passera R, Scozzari G, Verra M, Morino M (2012) Laparoscopy for rectal cancer reduces short-term mortality and morbidity: results of a systematic review and meta-analysis. 27:1485-1502. https://doi.org/10.1007/s00464-012-2649-x

4. Antoniou SA, Antoniou GA, Koch OO, Pointner R, Granderath F-A (2015) Laparoscopic colorectal surgery confers lower mortality in the elderly: a systematic review and meta-analysis of 66,483 patients. Surg Endosc 29:322-333. https://doi.org/10.1007/ s00464-014-3672-x

5. Greco M, Capretti G, Beretta L, Gemma M, Pecorelli N, Braga M (2013) Enhanced recovery program in colorectal surgery: a metaanalysis of randomized controlled trials. World J Surg 38:15311541. https://doi.org/10.1007/s00268-013-2416-8

6. Spanjersberg WR, van Sambeeck JDP, Bremers A, Rosman C, van Laarhoven CJHM. (2015) Systematic review and meta-analysis for laparoscopic versus open colon surgery with or without an ERAS programme. Surg Endosc 29:3443-3453. https://doi.org/10.1007/ s00464-015-4148-3

7. Pędziwiatr M, Kisialeuski M, Wierdak M, Stanek M, Natkaniec M, Matłok M, Major P, Małczak P, Budzyński A (2015) Early implementation of Enhanced Recovery After Surgery (ERAS(®)) protocol-compliance improves outcomes: a prospective cohort study. Int J Surg 21:75-81. https://doi.org/10.1016/j. ijsu.2015.06.087

8. Keller DS, Bankwitz B, Woconish D, Champagne BJ, Reynolds HL, Stein SL, Delaney CP (2013) Predicting who will fail early discharge after laparoscopic colorectal surgery with an established enhanced recovery pathway. Surg Endosc 28:74-79. https://doi. org/10.1007/s00464-013-3158-2

9. Hyman N, Manchester TL, Osler T, Burns B, Cataldo PA (2007) Anastomotic leaks after intestinal anastomosis. Ann Surg 245:254-258. https://doi.org/10.1097/01. sla.0000225083.27182.85

10. Smeets HJ, Kievit J, Dulfer FT, Hermans J, Moolenaar AJ (1994) Analysis of post-operative hypalbuminaemia: a clinical study. Int Surg 79:152-157 
11. Ryan AM, Hearty A, Prichard RS, Cunningham A, Rowley SP, Reynolds JV (2007) Association of hypoalbuminemia on the first postoperative day and complications following esophagectomy. J Gastrointest Surg 11:1355-1360. https://doi.org/10.1007/ s11605-007-0223-y

12. Labgaa I, Joliat G-R, Kefleyesus A, Mantziari S, Schäfer M, Demartines N, Hübner M (2017) Is postoperative decrease of serum albumin an early predictor of complications after major abdominal surgery? A prospective cohort study in a European centre. BMJ Open 7:e013966. https://doi.org/10.1136/ bmjopen-2016-013966

13. Hübner M, Mantziari S, Demartines N, Pralong F, Coti-Bertrand P, Schäfer M (2016) Postoperative albumin drop is a marker for surgical stress and a predictor for clinical outcome: a pilot study. Gastroenterol Res Pract 2016:8743187-8743188. https://doi. org/10.1155/2016/8743187

14. Veenhof AAFA, Vlug MS, van der Pas MHGM., Sietses C, Van Der Peet DL, de Lange-de Klerk ESM, Bonjer HJ, Bemelman WA, Cuesta MA (2012) Surgical stress response and postoperative immune function after laparoscopy or open surgery with fast track or standard perioperative care: a randomized trial. Ann Surg 255:216-221. https://doi.org/10.1097/SLA.0b013e31824336e2

15. Pędziwiatr M, Pisarska M, Kisielewski M, Matłok M, Major P, Wierdak M, Budzyński A, Ljungqvist O (2016) Is ERAS in laparoscopic surgery for colorectal cancer changing risk factors for delayed recovery? Med Oncol 33:25. https://doi.org/10.1007/ s12032-016-0738-8

16. Gordon PH, Nivatvongs S (2007) Principles and practice of surgery for the colon, rectum, and anus, 3rd edn. CRC Press, Boca Raton

17. Pisarska M, Pędziwiatr M, Małczak P, Major P, Ochenduszko S, Zub-Pokrowiecka A, Kulawik J, Budzyński A (2016) Do we really need the full compliance with ERAS protocol in laparoscopic colorectal surgery? A prospective cohort study. Int J Surgery 36:377-382. https://doi.org/10.1016/j.ijsu.2016.11.088

18. ECFDP (2013) Point prevalence survey of healthcare-associated infections and antimicrobial use in European acute care hospitals: 2011-2012. Publications Office of the European Union
19. Labgaa I, Joliat G-R, Demartines N, Hübner M (2016) Serum albumin is an early predictor of complications after liver surgery. Dig Liver Dis 48:559-561. https://doi.org/10.1016/j. dld.2016.01.004

20. Prichard RS, Manning BJ, Ryan A, Rowley S, Ravi N, Reynolds J (2006) Serum albumin levels as a predictor of post-operative complications in patients undergoing upper gastrointestinal surgery. Endoscopy. https://doi.org/10.1055/s-2006-956857

21. Mantziari S, Hübner M, Coti-Bertrand P, Pralong F, Demartines N, Schäfer M (2015) A novel approach to major surgery: tracking its pathophysiologic footprints. World J Surg 39:2641-2651. https://doi.org/10.1007/s00268-015-3181-7

22. Ritchie RF, Palomaki GE, Neveux LM, Navolotskaia O, Ledue TB, Craig WY (1999) Reference distributions for the negative acute-phase serum proteins, albumin, transferrin and transthyretin: a practical, simple and clinically relevant approach in a large cohort. J Clin Lab Anal 13:273-279

23. Fleck A, Raines G, Hawker F, Trotter J, Wallace PI, Ledingham IM, Calman KC (1985) Increased vascular permeability: a major cause of hypoalbuminaemia in disease and injury. Lancet 1:781-784

24. Tsamis D, Theodoropoulos G, Stamopoulos P, Siakavellas S, Delistathi T, Michalopoulos NV, Zografos GC (2012) Systemic inflammatory response after laparoscopic and conventional colectomy for cancer: a matched case-control study. Surg Endosc 26:1436-1443. https://doi.org/10.1007/s00464-011-2052-z

25. Kehlet H, Wilmore DW (2002) Multimodal strategies to improve surgical outcome. Am J Surg 183:630-641

26. Pędziwiatr M, Matłok M, Kisialeuski M, Migaczewski M, Major P, Winiarski M, Budzyński P, Zub-Pokrowiecka A, Budzyński A (2014) Short hospital stays after laparoscopic gastric surgery under an enhanced recovery after surgery (ERAS) pathway: experience at a single center. Eur Surg 46:128-132. https://doi. org/10.1007/s10353-014-0264-x

27. Kehlet H, Wilmore DW (2008) Evidence-based surgical care and the evolution of fast-track surgery. Ann Surg 248:189-198. https:// doi.org/10.1097/SLA.0b013e31817f2c1a 